\title{
Treatment Strategy Based on Multimodal Management Outcome of Cavernous Sinus Dural Arteriovenous Fistula (CSDAVF)
}

\author{
Byung Se Choi, MD',2, Jee Won Park, MD', Jong Lim Kim, MD1, Sung Youn Kim, MD', \\ Yang Shin Park, MD', Heon-Ju Kwon, MD', Deok Hee Lee, MD', Dae Chul Suh, MD'1
}

Purpose: Angiographic finding including venous drainage pattern should be correlated to the presenting symptom pattern (SxP) in CSDAVF. We present outcome of CSDAVF management and suggest a strategy according to SxP and type of treatment based on our experience.

Materials and Methods: We evaluated SxP, angiographic type (proliferative, restrictive or late restrictive), mode of treatment (embolization, Gamma Knife Radiation (GKR) or conservative management), mode of embolization (transarterial or transvenous), and final clinical status (cure, improvement, aggravation or no change). Ninety consecutive patients were included from a prospective database. The mean follow-up was 17 months. We compared the outcomes according to SxP, angiographic type, mode of treatment, and embolization using the chi-square or Fisher's exact test.

Results: Ninety patients with 34 proliferative, 40 restrictive, and 16 late restrictive types of CSDAVF were treated by embolization $(n=63)$, GKR $(n=7)$, and conservative management $(n=20)$. Cure or improvement was $91 \%$ after embolization, $88 \%$ after conservative management, and $72 \%$ after GKR. Following embolization, $100 \%$ of 24 proliferative types, $87 \%$ of 30 restrictive types, and $90 \%$ of 10 late restrictive types were cured or improved. Cure or improvement after transvenous embolization was $98 \%(43 / 44)$ compared with $88 \%(15 / 17)$ after transarterial embolization $(p=0.003)$.

Conclusion: Various factors of SxP, angiographic type, and mode of treatment should be considered in order to obtain a more favorable outcome for patients with CSDAVF. Embolization via venous approach tended to result in a more complete cure than that via arterial approach.

Key Words : Cavernous sinus; Dural arteriovenous fistula; Endovascular treatment; Transvenous embolization

\footnotetext{
'Department of Radiology and Research Institute of Radiology, Asan Medical Center, University of Ulsan, College of Medicine, Seoul, Korea ${ }^{2}$ Department of Radiology, Seoul National University College of Medicine, Seoul National University Bundang Hospital, Seongnam, Korea This study was supported by a grant of the Korea Healthcare technology R\&D Project, Ministry of Health \& Welfare, Republic of Korea (A080201).

Received August 23, 2010;

accepted after revision November 20, 2010.

Correspondence to: Dae Chul Suh, MD, Department of Radiology, Asan Medical Center, University of Ulsan, College of Medicine, 86 Asanbyeongwon-gil, Songpa-gu, Seoul 138-736, Korea.

Tel. 82-2-3010-4366 Fax. 82-2-476-0090 E-mail: dcsuh@amc.seoul.kr

Neurointervention $2011 ; 6: 6-12$

This is an Open Access article distributed under the terms of the Creative Commons Attribution Non-Commercial License (http://creativecommons.org/licenses/by-nc/3.0) which permits unrestricted non-commercial use, distribution, and reproduction in any medium, provided the original work is properly cited.
} 


\section{Outcome of Cavernous Sinus Dural Arteriovenous Fistula}

Among dural arteriovenous fistulas (DAVFs) with an abnormal direct connection between a meningeal artery and a meningeal vein or dural venous sinus, cavernous sinus dural arteriovenous fistula (CSDAVF) differs in several aspects from DAVF involving other dural sinuses (1). Anatomically, the cavernous sinus (CS) is an extradurally located sinus while other dural sinuses are located between two dural walls in the cranial cavity. Compared with the transverse-sigmoid sinus as the most frequent site of occurrence in western countries, the CS is the most common location of DAVF in Asians (2-4).

CSDAVF presents with three distinctive angiographic patterns, i.e. the proliferative type (PT), restrictive type (RT), and late restrictive type (LRT) related to the four presenting symptom patterns (SxP) of orbital SxP, cavernous SxP, ocular SxP, and cerebral SxP according to the status of the CS confluence (5). This concept associated with the presenting SxP and the CS venous drainage patterns provided a practical basis for assessing the disease status and for planning therapeutic decisions (5). Progressive restrictive change of the venous drainage of the angiographic type in CSDAVF cannot only affect the presenting SxP, but can also modify the strategy regarding the choice of treatment modality.

The treatment options for these lesions include conservative management such as manual compression of the ipsilateral carotid artery, transarterial and/or transvenous embolization, and Gamma Knife Radiation (GKR). Some authors prefer endovascular therapy as the primary treatment, whereas others recommend conservative management or even radiation-induced obliteration.

The clinical SxP and signs of CSDAVF are usually known to be benign as CS has sufficient venous drainage routes including the superior ophthalmic vein (SOV), inferior and superior petrosal sinuses (IPS and SPS), superficial middle cerebral vein (SMCV), and the coronary sinus on the opposite side of the CS (5). As the symptoms of CSDAVF are very diverse and fluctuate, analysis of the symptomatology related to the angiographic findings does not always correspond to the disease status, and therefore the optimal treatment for CSDAVF is not immediately obvious. Furthermore, although most studies report an immediate functional outcome after treatment, few have been reported according to the long-term patient status. We evaluated and compared the outcome of CSDAVF according to the SxP and type of treatment in order to propose a treatment strategy for each disease phase and for each treatment modality.

\section{MATERIALS AND METHODS}

\section{Subjects}

We retrospectively analyzed 90 consecutive patients with CSDAVF in the prospectively collected database between May 1991 and July 2007 during the mean 17month follow-up period. Patient age ranged from 20 to 80 years (mean 57; male-to-female ratio, 24:66). Written informed consent for the therapy was obtained from each patient and their family after the procedure had been fully explained. This study was approved by our institutional review board.

Based on the cerebral angiographic findings, we defined the disease as proliferative, restrictive or late restrictive type and patient symptoms as having an orbital, cavernous, ocular or cerebral symptom pattern, as previously described (5). The proliferative type (PT) revealed numerous arterial feeders to CS. Arterial feeders, especially from the middle meningeal artery and ophthalmic artery, converge around CS in addition to the dural branches of ICA. The number of feeders was not quantified because of many feeders with small size and large number. There was a large amount of arteriovenous shunt (AVS), and the shunt flow was relatively rapid while filling $\mathrm{CS}$ as well as the antegrade and retrograde venous routes. The venous phase showed well-preserved antegrade flow into IPS. Both CSs usually filled completely with the shunted flow regardless of the involved side of CS. There was a bulging in the sinus wall because of the shunted venous flow. The restrictive type (RT) showed multiple arterial feeders, but not as many as the number of arterial feeders in PTs. Differentiation between PT and RT was that each arterial feeder converging to the wall of the dilated CS could be delineated in RT but not in PT. The venous phase showed obliteration of antegrade flow most commonly of IPS and opening of retrograde flow into SOV and/or cortical veins. AVS still existed, although the flow was not as rapid as in PT. CS wall margin was not delineated completely because of deformity (loss of normal sinus contour) and lobulation of CS wall. Such lobulated change of CS margin seemed to be caused by a deformed outline of the sinus wall caused by fibrosis or change caused by organizing thrombosis $(6-8)$. The late restrictive type (LRT) showed only a few arterial feeders with sluggish retrograde venous flow. Constrictive change (pruning) of the draining veins in the retrograde venous outflow was the outstanding feature of this type. There was 
flow stasis in CS or draining vein even in the late venous phase. Such sluggish venous outflow seemed to be related to the constrictive venous change caused by the long-standing elevated venous pressure.

The orbital symptom pattern (OrbSxP) was caused by the retrograde venous flow and/or pressure from CS including chemosis, exophthalmos, periorbital pain, and eyelid swelling. The cavernous symptom pattern (CavSxP) included ptosis, diplopia, anisocoria, and ophthalmoplegia caused by cranial nerve deficits that seemed to be related to bulging or elevated pressure of $\mathrm{CS}$ and/or perhaps to the steal phenomenon of blood supply to the cranial nerves (9). The ocular symptom pattern $(\mathrm{OcuSxP})$ related to increased venous pressure draining the eyeball was decreased vision (when there is a patient symptom or interocular difference of $>0.2$, i.e., 2 lines difference in the Snellen visual acuity chart or its equivalent), increased intraocular pressure $(>20$ $\mathrm{mm} \mathrm{Hg}$ or a interocular difference of $>5 \mathrm{~mm} \mathrm{Hg}$ ), severe ocular (eyeball) pain, glaucoma, and retinal hemorrhage. The cerebral symptom pattern (CerSxP) was related to reflux of AVS into SMCV or of the petrosal vein into the perimesencephalic vein and cerebellar vein, thus leading to infarction or venous congestion in the basal ganglia, brain stem, or cerebellum leading to seizure or to hemorrhage.

The presenting SxP of the CSDAVFs were cavernous in 63 patients $(70 \%)$, orbital in 54 patients $(60 \%)$, ocular in 53 patients $(59 \%)$, and cerebral in six patients $(7 \%)$, according to the order of frequency. Ninety patients revealed 34 proliferative, 40 restrictive, and 16 late restrictive angiographic types. Of 34 patients with the PT, 24 underwent embolization, one GKR, and nine patients had conservative treatment. Of the 40 patients with the RT, 30 underwent embolization, five GKR, and five patients had conservative treatment. Of the 16 patients with the LRT, 10 underwent embolization, one GKR, and five patients had conservative treatment.

Overall, transarterial or transvenous embolization was done in 63 patients $(71 \%)$, GKR in 7 patients $(8 \%)$ and conservative management in 20 patients $(21 \%)$. Of the 63 patients treated by embolization, 44 underwent transvenous embolization, 19 underwent transarterial embolization, and 14 underwent both routes of embolization during 81 procedures. If the first mode of embolization failed or was incomplete and the next mode of embolization could lead to total obliteration of the DAVF, we regarded the last embolization route as the main route of embolization.

\section{Treatment and Follow-up}

General approaches for the treatment of CSDAVF include transarterial or transvenous embolization, GKR, and conservative management. The benign nature of the symptom category, such as orbital SxP, is frequently associated with CSDAVFs, failure of the main route of embolization or patient refusal of treatment. Therefore, some DAVFs can be treated conservatively together with manual compression performed by the patient with instructions to compress the carotid artery with their contralateral hand for 1030 seconds per compression six times an hour while awake (10).

Embolization included both transarterial and transvenous approaches. The transarterial approach to the external carotid artery was performed via the femoral artery in order to obliterate the arteries feeding the fistula, and using the coaxial technique. Polyvinyl alcohol particles $(150-500 \mu \mathrm{m})$ were used as the main embolic material. The transvenous approach was performed via the inferior or superior petrosal sinus or via the facial vein. We preferred transvenous approach via the inferior petorsal sinus even if there was occlusion of the inferior petrosal sinus in the restrictive or late restrictive type. If the transvenous approach failed, an approach from the contralateral side was also attempted (Fig. 1). We used direct puncture via the SOV when use of the transfemoral venous approach was not possible. After the transvenous route to the fistula was secured, we used non-detachable and/or detachable coils to obliterate the fistula.

Angiographically, total occlusion was defined as complete occlusion of the AVF, subtotal occlusion as a small residual stagnant shunt that was considered likely to thrombose, and partial occlusion as the presence of residual fistula. Total and subtotal occlusions were considered as successful treatment results.

Clinical follow-up was primarily obtained by both interventional neuroradiologist and neurologist. In case of any delay in patient recovery or a clinical suspicion of recurrent disease, the imaging study was repeated. The final clinical status was defined as cure or improvement of the symptoms related to the lesion or no change of symptoms and aggravation as newly developed symptoms or aggravated status of preexisting symptoms detected during follow-up. We compared each group's outcomes according to the SxPs, angiographic types, treatment types, and embolization routes using the chi-square test or Fisher's exact test. 


\section{Outcome of Cavernous Sinus Dural Arteriovenous Fistula}
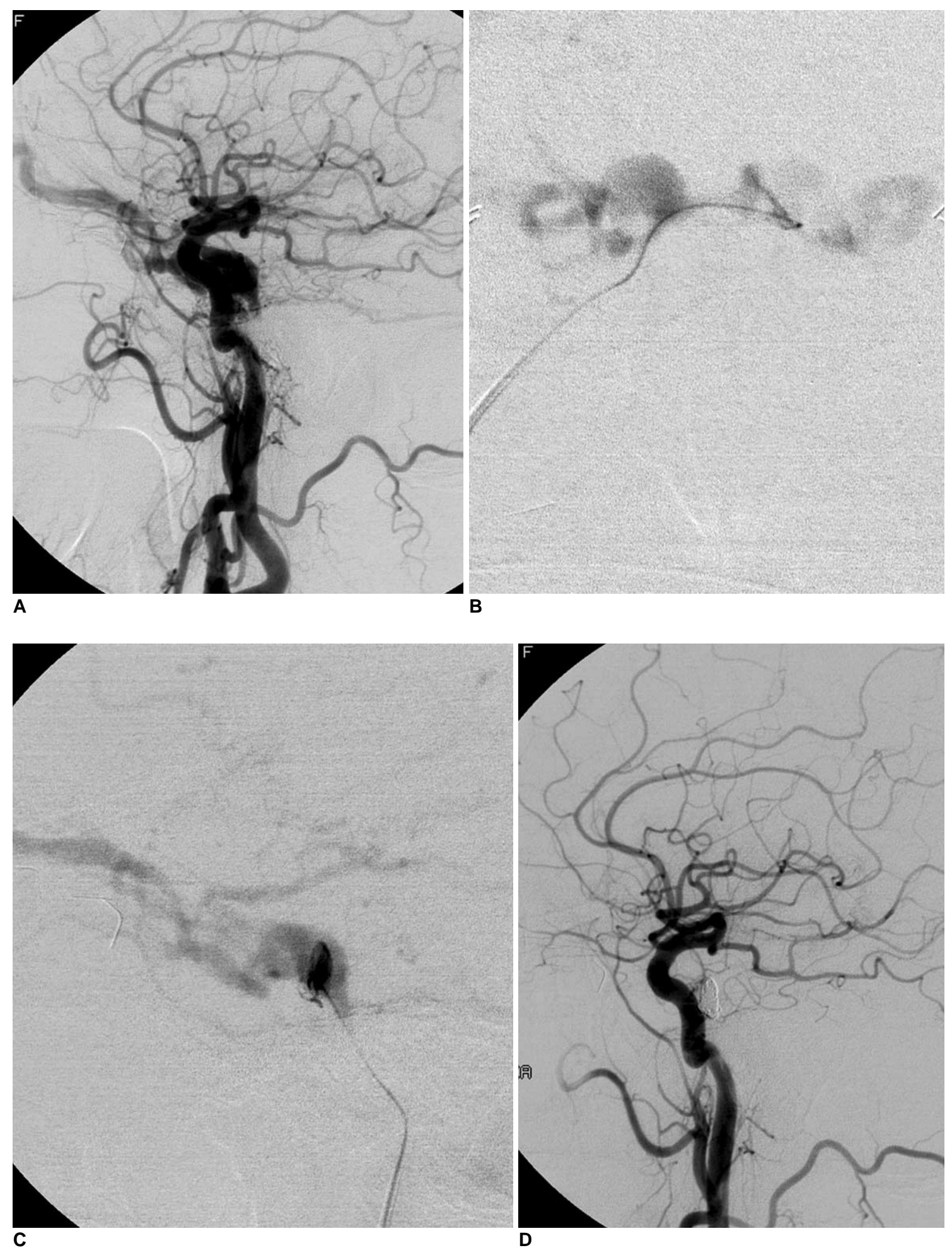

Fig. 1. A 68-year-old female presented with chemosis, exophthalmos, diplopia, and ocular pain on both sides. Her occluar pressure was $33 / 33 \mathrm{mmHg}$ (right/left). (A) Left internal carotid arterigram shows a dural arteriovenous fistula in the cavernous sinus. Microcatheter angiogram showed that both dilated cavernous sinuses were filled on the anterioposterior view (B) after a venous approach through the right inferior petrosal sinus into the left cavernous sinus as well as into the fistular pouch as seen on the lateral view (C). (D) The final left internal carotid arteriogram revealed that complete devascularization was achieved after coil embolization of the fistular pouch. On the two-month follow-up, the patient's symptoms and signs had completely disappeared and her ocular pressure had returned to normal $(15 / 14 \mathrm{mmHg})$. 
Table 1. Outcome Summary Following Multimodality Treatment

\begin{tabular}{|c|c|c|c|c|c|}
\hline & \multicolumn{2}{|c|}{ Embolization } & \multirow{2}{*}{ GK } & \multirow{2}{*}{$\begin{array}{l}\text { Conservative } \\
\text { Management }\end{array}$} & \multirow{2}{*}{ Total } \\
\hline & Arterial Approach & Venous Approach & & & \\
\hline Good outcome & 15 & $43^{*}$ & 5 & 14 & 77 (86\%) \\
\hline Poor outcome & 2 & 1 & 1 & 4 & $8(9 \%)$ \\
\hline Not available & 2 & 0 & 1 & 2 & $5(5 \%)$ \\
\hline Total & 19 & 44 & 7 & 20 & 90 \\
\hline
\end{tabular}

Note.-Good outcome $=$ cure or improvement; Poor outcome = aggravation or no change in the symptoms; GK = gamma knife radiation therapy.

${ }^{*}=$ embolization via the venous approach led to a better outcome than via the arterial route (Fisher's exact test, $p=0.003$ )

\section{RESULTS}

The baseline demographic characteristics are presented in Table 1. The mean age at diagnosis was 56 years (range, $17-85$ years). The mean follow-up interval was 17 months. Sixty-six patients $(73 \%)$ were women and 24 were men. The cure and improvement rates were $95 \%(58 / 61)$, respectively, after embolization, 83\% (5/6) after GKR, and 78\% (14/18) after conservative treatment. Following embolization, angiographic total occlusion was achieved in 50 patients, subtotal in six, and partial in seven patients. The final clinical status revealed that $100 \%$ of $24 \mathrm{PTs}$, $87 \%$ of 30 RTs, and $90 \%$ of 10 LRTs were cured or improved. No statistically significant difference was found in the distribution of SxPs between the angiographic types or in the outcomes according to the SxPs.

In patients who underwent transvenous embolization, the cure and improvement rates were 98\% (43/44), respectively, compared with $88 \%(15 / 17)$ in patients who underwent transarterial embolization $(\mathrm{p}=0.003)$ (Table 1).

\section{DISCUSSION}

Our study, which was based on a single large referral center experience, reveals that overall outcome of CSDAVF treatment was better after embolization than after conservative management and GKRS. In addition, transvenous embolization achieved a cure and improved states more commonly than arterial embolization. This finding was similar to the treatment results for DAVF seen in the literature (11). However, the treatment strategy should focus on both the patient's symptom pattern and the angiographic findings including the venous drainage pattern which can affect the decision regarding the treatment modality. Therefore, a simple comparison of the outcomes among treatment modalities must be carefully analyzed. There sometimes exist some therapeutic dilemma in decision making in patients with CSDAVF those have benign symptom but posterior fossa and/or cortical venous drainage. When embolization is used with the CSDAVF treatment, embolization via a transvenous approach is currently considered a good therapeutic option for patients with cortical venous drainage or malignant symptoms such as ocular and cerebral symptoms (5).

Conservative management can be offered in patients with benign symptom category and embolization in patients in the malignant symptom category. However, some patients (about $4 \%$ ) can progress to malignant symptom category during follow-up period which finally can reveal cortical venous drainage (12). Our results can explain in some aspect such angiographic progression leading to more malignant symptom category possibly change into restrictive or late restrictive venous drainage pattern. In addition to the presenting symptom pattern, therefore, angiographic type including the venous drainage pattern into the cortical veins or posterior fossa veins is critical for deciding the optimal treatment modality as well as the approach route for the embolization. In the restrictive phase in which the antegrade venous route is occluded, a transvenous approach can be through the occluded sinus or facial vein or through the SOV. Even though such venous approach techniques are highly dependent on the operator's expertise because incomplete or inappropriate embolization can carry the subsequent risk of a rerouting phenomenon of residual venous drainage which can lead to fatal hemorrhage or venous infarction (13).

As steel coils and sclerosing liquid injections into the CS were performed via the SOV (14), complete 


\section{Outcome of Cavernous Sinus Dural Arteriovenous Fistula}

CSDAVF obliteration can also be obtained via an inferior petrosal sinus route which undoubtedly represents the easiest, shortest, and safest approach even in patients with inferior petrosal sinus thrombosis or occlusion. A superior petrosal sinus approach has been reported to be an alternative to catheterization of the inferior petrosal sinus (15). As an alternative to the inferior or superior petrosal sinus pathways, a facialophthalmic route or direct puncture of the SOV may also be used. Arterial embolization can additionally be considered in patients in whom venous access is not possible (16).

Recent studies of the efficacy of stereotactic radiation have reported complete occlusion in $44-87 \%$ of cases, which is similar to our results $(17-19)$. Advantages of this technique include decreased invasiveness and fewer short-term complications, whereas a disadvantage is the delayed response (approximately 6-12 months) after irradiation and possible aggravation of the symptoms. Therefore, GKR needs to remain the last treatment option as otherwise the malignant symptom pattern cannot be managed. The combined use of GKR and transarterial embolization with particles can enhance the effectiveness of this technique and thus reduce the risk of worsening symptoms during the follow-up period (19-21).

Because of the low prevalence of aggressive symptoms and the relatively high rates of spontaneous regression, it is suggested that the majority of cases be treated conservatively for $1-3$ months (2). However, cases with progressive symptoms and dangerous drainage patterns require more aggressive treatment and cases that have remained stable for a few months should be treated with irradiation or intervention. One should also be aware that the low-risk drainage patterns of DAVFs can develop into high-risk patterns with progressive thrombosis or restriction of the CS outlet $(5,12,22)$.

In conclusion, various factors of the $\mathrm{SxP}$, angiographic type, and mode of treatment should all be considered in order to obtain a more favorable outcome for CSDAVF. In our study, embolization led to a more favorable outcome compared to conservative management or GKR. Therefore, we also suggest that a successful outcome can be obtained by embolization using a venous approach more often than by using an arterial approach.

\section{References}

1. Berenstein A, Lasjaunias PL, Ter Brugge K. Dural arteriovenous shunts. In: Berenstein A, Lasjaunias PL, Ter Brugge K, eds.
Surgical Neuroangiography. 2004: New York: Springer 565-607

2. Cognard C, Gobin YP, Pierot L, Bailly AL, Houdart E, Casasco A, et al. Cerebral dural arteriovenous fistulas: clinical and angiographic correlation with a revised classification of venous drainage. Radiology 1995;194:671-680

3. Kim MS, Han DH, Kwon OK, Oh CW, Han MH. Clinical characteristics of dural arteriovenous fistula. J Clin Neurosci 2002;9:147-155

4. Chung SJ, Kim JS, Kim JC, Lee SK, Kwon SU, Lee MC, et al. Intracranial dural arteriovenous fistulas: analysis of 60 patients. Cerebrovasc Dis 2002;13:79-88

5. Suh DC, Lee JH, Kim SJ, Chung SJ, Choi CG, Kim HJ, et al. New concept in cavernous sinus dural arteriovenous fistula: correlation with presenting symptom and venous drainage patterns. Stroke 2005;36:1134-1139

6. Houser OW, Campbell JK, Campbell RJ, Sundt TM, Jr. Arteriovenous malformation affecting the transverse dural venous sinus--an acquired lesion. Mayo Clin Proc 1979;54:651-661

7. Aminoff MJ. Vascular anomalies in the intracranial dura mater. Brain 1973;96:601-612

8. Kurata A, Miyasaka Y, Oka H, Irikura K, Tanaka R, Ohmomo T, et al. Spontaneous carotid cavernous fistulas with special reference to the influence of estradiol decrease. Neurol Res 1999;21:631-639

9. Lasjaunias P, Chiu M, ter Brugge K, Tolia A, Hurth M, Bernstein M. Neurological manifestations of intracranial dural arteriovenous malformations. J Neurosurg 1986;64:724-730

10. Higashida RT, Hieshima GB, Halbach VV, Bentson JR, Goto K. Closure of carotid cavernous sinus fistulae by external compression of the carotid artery and jugular vein. Acta Radiol Suppl 1986; 369:580-583

11. Roy D, Raymond J. The role of transvenous embolization in the treatment of intracranial dural arteriovenous fistulas. Neurosurgery 1997;40:1133-1141

12. Kim DJ, Ter Brugge K, Krings T, Willinsky R, Wallace C. Spontaneous angiographic conversion of intracranial dural arteriovenous shunt: long-term follow-up in nontreated patients. Stroke 2010;41:1489-1494

13. Kim DJ, Kim DI, Suh SH, Kim J, Lee SK, Kim EY, et al. Results of transvenous embolization of cavernous dural arteriovenous fistula: a single-center experience with emphasis on complications and management. AJNR Am J Neuroradiol 2006;27:2078-2082

14. Halbach VV, Higashida RT, Hieshima GB, Reicher M, Norman D, Newton TH. Dural fistulas involving the cavernous sinus: results of treatment in 30 patients. Radiology 1987;163:437-442

15. Mounayer C, Piotin M, Spelle L, Moret J. Superior petrosal sinus catheterization for transvenous embolization of a dural carotid cavernous sinus fistula. AJNR Am J Neuroradiol 2002;23:11531155

16. Theaudin M, Saint-Maurice JP, Chapot R, Vahedi K, Mazighi M, Vignal C, et al. Diagnosis and treatment of dural carotidcavernous fistulas: a consecutive series of 27 patients. J Neurol Neurosurg Psychiatry 2007;78:174-179

17. O'Leary S, Hodgson TJ, Coley SC, Kemeny AA, Radatz MW. Intracranial dural arteriovenous malformations: results of stereotactic radiosurgery in 17 patients. Clin Oncol (R Coll Radiol) 2002;14:97-102

18. Guo WY, Pan DH, Wu HM, Chung WY, Shiau CY, Wang LW, et al. Radiosurgery as a treatment alternative for dural arteriovenous 


\section{Byung Se Choi, et al.}

fistulas of the cavernous sinus. AJNR Am J Neuroradiol 1998:19:1081-1087

19. Pollock BE, Nichols DA, Garrity JA, Gorman DA, Stafford SL. Stereotactic radiosurgery and particulate embolization for cavernous sinus dural arteriovenous fistulae. Neurosurgery 1999;45:459-466

20. Lewis AI, Tomsick TA, Tew JM, Jr. Management of tentorial dural arteriovenous malformations: transarterial embolization combined with stereotactic radiation or surgery. J Neurosurg
1994;81:851-859

21. Friedman JA, Pollock BE, Nichols DA, Gorman DA, Foote RL, Stafford SL. Results of combined stereotactic radiosurgery and transarterial embolization for dural arteriovenous fistulas of the transverse and sigmoid sinuses. J Neurosurg 2001;94:886-891

22. Satomi J, van Dijk JM, Terbrugge KG, Willinsky RA, Wallace MC. Benign cranial dural arteriovenous fistulas: outcome of conservative management based on the natural history of the lesion. J Neurosurg 2002;97:767-770 